\title{
The Hardest Part Is Knowing I Will Survive: The Use of Music and Creative Mediums to Enhance Empathy and Facilitate Life-Long Distance Learning in Professionally Qualified Clinicians
}

\author{
Saskia Keville ${ }^{1}$, Katherine Nutt ${ }^{2}$, Isabel Brunton ${ }^{3}$, Carly Keyes ${ }^{4} \&$ Erasmo Tacconelli $^{5}$ \\ ${ }^{1}$ Principal Lecturer and Clinical Psychologist, Department of Psychology and Sports Sciences, University of \\ Hertfordshire, Hatfield, United Kingdom \\ ${ }^{2}$ Mid Essex Hospital Services NHS Trust, United Kingdom \\ ${ }^{3}$ Northamptonshire Healthcare NHS Foundation Trust and Anglia Ruskin University, United Kingdom \\ ${ }^{4}$ Hertfordshire Partnership University NHS Foundation Trust, United Kingdom \\ ${ }^{5}$ East London Foundation NHS Trust, United Kingdom \\ Correspondence: Saskia Keville, Department of Psychology and Sports Sciences, University of Hertfordshire, College \\ Lane Campus, Hatfield, Herts. AL10 9AB. United Kingdom
}

Received: June 4, 2019 Accepted: July 30, $2019 \quad$ Online Published: August 19, 2019

doi:10.11114/jets.v7i10.4463 URL: https://doi.org/10.11114/jets.v7i10.4463

\begin{abstract}
Music is an experience that can cross personal and professional domains alongside cultural, gender, age and generational boundaries; it can also enhance the learning process through emotional processing and connection. This paper focuses on the learning experience of qualified clinical psychologists (CPs) working in the United Kingdom. This group of CPs had experience of undertaking experiential learning and reflective writing during their professional training. It considers the potential to continue a learning process, 3 years post qualification, through long distance methods using vignette-based material.

Empathising with, and understanding, the position of others from differing backgrounds is an important competency within the therapeutic work of CPs and this comes alongside acknowledging and understanding ones' own experiences, both past and present. CPs work with difficult life experiences and complex issues; connecting constantly can be exhausting and, perhaps, unrealistic. Yet, to truly empathise one must connect with, and understand, the lived experiences of others. We will consider what helps and hinders this process, and how music and other creative mediums can be effectively used in learning even via long distance methods. We will further consider how CPs may be well placed to enhance the learning about, and processing of, difficult emotional experiences for themselves, other clinicians and the people they might work with.
\end{abstract}

Keywords: life-long learning, distance learning, music, empathy, reflective practice, experiential avoidance, clinicians

\section{Introduction}

Learning can be a lifelong process, in both personal or professional domains. Intensive learning tends to occur through traditional education environments and methods via undergraduate and post-graduate degrees, professional training or continuing professional development (CPD). For clinicians working in clinical practice this training is crucial as they seek to understand and ameliorate the wellbeing of those seeking their help, in addition to keeping abreast of developments in knowledge to competently undertake this.

Clinical psychologists (CPs) work with difficult life experiences and complex issues in people, families, and systems; to be an effective practitioner they must connect with, and understand, the lived experiences of others. Empathising with, and understanding, the position of others from differing backgrounds is an important competency within the therapeutic work of CPs (British Psychological Society (BPS), 2016). Yet, connecting constantly can be exhausting and, perhaps, unrealistic. Indeed, there can be a natural tendency for people, including clinicians, to use suppression via experiential avoidance to manage events and emotions perceived to be too distressing (Hayes, Strosahl \& Wilson, 2003); with the impact of this suppression maintaining or even heightening distress (Purdon, 2004). 
As clinicians there can be consequences to these suppressive tendencies that may impact on psychological outcomes within therapeutic work for the clinician and those they might see. In the UK, perhaps, this is exacerbated by recommendations within Improving Access to Psychological Therapies (IAPT: Clark, Layard, Smithies, Richards, Suckling \& Wright, 2009) where the focus can be on short term interventions that result in rapid, positive outcomes despite these outcomes being harder to attain when working with complex presentations. For these more complex scenarios, to enable the processing of difficult emotional experiences and memories many clinicians acknowledge the value of focusing on the past alongside working with current distress. Further, IAPT has meant other professions now offer first contact therapies and support for psychological issues resulting in CPs working predominantly with complex presentations. Consequently, finding ways to support clinicians to remain connected may be crucial in managing clinician burnout. This is particularly pertinent given managing distress in clinical working contexts can require courage, confidence and the ability of clinicians to process the impact complex work can have on them.

$\mathrm{CPD}$ is one way for qualified practitioners to gain additional skills and enhance practice. It usually occurs via off site courses, conferences and workshops utilising clinically relevant material, didactic presentations of knowledge, theories and research, and experiential learning methods to develop skills. All of this requires the ability to take time off clinical work. Again, this might not always be realistic in the busy lives of the working clinician and alternative learning opportunities may be required to help develop and build depth and breadth to knowledge and experience.

\subsection{The therapeutic Use of Music}

The use of music for health and wellbeing is well established in many educational and therapeutic contexts (MacDonald, Kreutz \& Mitchell, 2014). Indeed, there are emotional, social and communicative values to music (MacDonald et al., 2014) and these can transfer into the learning processes of CPs in training (Keville, Nutt, Brunton, Keyes \& Tacconelli, 2018). Yet, whilst the interest in music for health and well-being crosses disciplines and research methodologies (MacDonald et al., 2014), it is relatively unexplored in clinical psychology apart from anecdotal accounts. For example, Winter (2017) and his therapeutic use of music in Sierra Leone; and in training (Keville et al., 2018). In this current paper, inspiration for the use of music in learning derives from an awareness of its processing and connective power; the work of Lucy Kaplansky who trained as a CP in the US highlights this. Her music and lyrics blend a deep understanding of people with a similarly deep understanding of music. In releasing her album Reunion in 2012 she wrote:

'It's inevitable that as you get older and your life deepens you find more ways of connecting to an even larger circle of people. This album is largely about reunions with family and deepening social connections with friends and audiences through my music.' (Retrieved from: http://lucykaplansky.com/bio/_)

Given the potential for music to work positively across emotional, social and communicative domains, it could improve efficacy in interventions through those domains (Keville et al., 2018), whilst also facilitating the development of clinicians' understanding and knowledge.

\subsection{The Role of Music in Ameliorating or Maintaining Our and Others' Distress: The Hardest Part is Knowing I'll} Survive

Acknowledging the relative dearth of research exploring the role music might have in maintaining or ameliorating distress, Miranda, Gaudreau, Debrosse, Morizot \& Kirmayer (2015) highlighted that listening to music that does not evoke positive feelings may increase sub-clinical experiences of distress for some vulnerable people. There was no conclusion why, yet it may be due to the ruminative and worry-based processes that maintain emotional disorders (Wells, 2000). Miranda et al. (2015, p526) concluded people should be encouraged to maintain a 'healthy' balance by listening to music that evokes positive experiences, alongside preferences for more emotive music. However, there are anecdotal accounts of the value of music and songs to work with, and process, distress; and this paper considers if there is scope, when properly scaffolded (Wood, Bruner \& Ross, 1976), to enable more functional and helpful connections with distress through the use of music and other creative mediums, particularly in learning.

Further, crucial to the context of CP learning opportunities and therapeutic work is the use of language to elicit meaning; interestingly, findings from measurements of electric brain activity suggest that general responses to music also recruit cognitive and language processes (Flores-Gutiérrez, Díaz, Barrios, Favila-Humara, Guevara, del Río-Portilla \& Corsi-Cabrera, 2007), highlighting an interrelatedness between these components. This could enable the use of music alongside language-based therapies and learning, potentially enhancing therapeutic and learning processes.

Given music can enhance learning and is an experience that can cross multiple domains and boundaries, this paper seeks to explore methods of learning through the experiences of qualified CPs working in busy health-care settings in the United Kingdom (UK). It considers CPs' ability to emotionally connect with the people they see whilst working in these busy environments. It also considers whether alternative learning methods can facilitate life-long learning. We will 
consider the experience of using creative mediums, including music, to elucidate understanding of a lived experience of a referral and clinicians' ability to see beyond the printed words to the personhood of those referred to health-care services. Alongside this we will consider what helps and hinders learning and connection.

\section{Method}

Three qualified CPs working in three different UK NHS services agreed to participate in a novel distance-learning task involving music. They had all trained through NHS funding on one doctoral CP training programme. These CPs had participated 6 years earlier in a similar group-based task during their training (Keville et al., 2018). They all had experience of reflective writing throughout their training as this formed part of their overall assessment on the programme.

\subsection{The Vignette}

For this current task the vignette was based on a typical trauma referral to a Community Adult Mental Health Team (CMHT). Patricia (a pseudonym) was referred following a car accident involving her husband (who died in the accident) and 3 children. Both Patricia and her children were significantly injured and thus, her family and her husband's family provided support in the aftermath. It is important to consider adults in the context of their lives; thus, the vignette gave opportunities to examine issues from multiple perspectives across the lifespan. Alongside this was the potential to explore personal, professional, psychological, physical, neurological and societal issues presented through the vignette materials.

\subsection{Procedure}

The structure of the learning task simulated a typical referral process (letters and reports). Firstly, a GP referral letter was sent to the clinicians in the post for independent reading (a KitKat chocolate bar was also included for each learner). Once receipt was acknowledged the individuals received part 2, a CP assessment report, via email. They reviewed the materials in their own time and space.

After acknowledgment of receipt, part 3 was sent via email to the clinicians, again for independent experiencing of the materials; this involved a link to a song interlinked with the vignette: 'Boulder to Birmingham' written by Emmylou Harris and Bill Danoff. In constructing the vignette, it is crucial that the song communicates with the clinical letters, with details from the song being matched in the vignette. This song talks about an acute experience of loss written when one of the songwriter's was grieving.

Part 4 was sent through the post and, again, included KitKats in addition to letters written and published by the three children to their Dad on Fathers' Day. These were real letters (confidentiality was ensured throughout and all materials were used with consent) and their Mum (named as Patricia in the vignette) had added an addendum:

$\mathrm{Xx}-\mathrm{X}, \mathrm{X}$ and $\mathrm{X}$ 's dad - died 21/2 years ago. We are not Christians and so when they asked where Daddy had gone we invented a place where he would have all the things he liked: KitKats, Arsenal* winning all the time and the PlayStation - it's called KitKat Land. Mum

(*Arsenal are a UK premier league football team)

The KitKat's sent with part 1 initially seemed unconnected with the vignette. By part 4 with the independent review of the children's letters, it was hoped the KitKat's would produce deeper emotional meaning and connection for the clinicians. This simulates real life where clinicians can never be fully prepared for the experiences, emotions and connections that might happen in their personal lives or clinical practice.

\section{The Reflective Narratives}

Once all materials were released the CPs agreed to write independent reflective pieces. They were explicitly asked how they experienced the music and creative mediums used within the task. To ensure the authors retained control over what was voiced and to celebrate each unique and diverse position the narratives were written independently. As authors we were aware reflections were influenced by the audience they were written for and represented a small portion of the thoughts and feelings experienced during this process. Therefore, these narratives remained partial, incomplete and open to further elaboration and/or reinterpretation by any reader, including the authors.

\subsection{Katherine}

'I was aware this would be an emotive case and evocative music would feature at some point to highlight the emotionality of the situation the referred individual was facing. It was interesting that even with this expectation I was still guarded in my emotional responding and unprepared for the connection the music brought. I felt I was being empathic and thinking through what they may be experiencing but at no point had I made emotional connections to any of my own personal, or professional, experiences. 
The content of the referral and my style of responding reminded me of an idea discussed by Shankar, Nolte and Trickey (2017) which proposes that in facing the loss of a child parents must oscillate between their connection to the lost child and their grief, or, to their remaining children. I imagined Patricia must feel the competing demands of both being present for her children and containing their loss, and the desire to lose herself in her own grief. The line 'the hardest part is knowing I'll survive' highlights the absolute desolation and self-involving nature of this experience. It wasn't until I listened to the song that I was transported to a memory of my grandma on the night my grandfather died asking his lifeless body over and over 'oh my love how could you leave me'. There was no consideration for her daughters or grandchildren just a need to be with her love and her pain.

I found myself thinking of the oscillation we experience as professionals - a desire and need to connect with both our client's and our own humanity whilst needing to disconnect from this to protect both parties. I recently received a referral for a father facing the imminent and unexpected loss of his wife and wanting support with how to break this news to their young child. I remember consciously thinking I cannot connect too closely to this for fear of being overwhelmed, whilst simultaneously knowing this family needed a human to be with their experience, not another professional.

This process left me wondering how beneficial it might be to model to our clients how we might connect to an emotional experience without becoming overwhelmed by it. The heightened emotional connection following listening to the music led to me feeling more creative about ways of working with her and the system around her. It also helped connect me to an element of risk that had been obscured whilst I had been more disconnected. However, I also started to feel quite helpless and hopeless and it felt important not to become lost in that part of the emotional connection.

I wonder if some of what enables music to be a tool for connection to our inner emotional worlds is that it feels controllable. It allows us to connect to an experience and to feel able to 'turn this off'. In this way it can feel quite safe and containing. It allows us to be with something but also to step away from that, and then return, but the important part is we were there.'

\subsection{Isabel}

'So, I got the referral letter and thought I empathised for the person in the letter; but the empathy was cold and lacking in emotion. If I'm honest, my thoughts were, "another trauma case". We've had a lot of referrals for trauma symptoms recently where I work. The words on the referral letter that stuck out were, "flashbacks", "trauma", "loss", and "intrusive images". The reason these words stuck out was not because of any kind of emotion for the family, but because I was robotically drawn to identifying at a quick glance the kind of presenting problem I might face. I tried to work out what model of therapy might be useful, how long the therapy might take and whether there would be time to fit this client in to my existing workload. I generally consider myself caring and human, but my perspective and connection with the client in the referral letter was anything but.

When I heard the song for the first time, it was images and feelings that then stuck out for me, rather than words. And these did not arise from black and white type on a page, but from images created in my own mind, bought on by the music and lyrics I heard. These images and feelings included "love", "grief", "despair", "longing", "regret", "sadness" and "guilt". Images and feelings that have no words also materialised and cannot be made concrete. When I heard the music I felt, I didn't just think as I did when I read the referral letter. The music enabled connection by enabling feeling.

After hearing the song, rather than see Patricia as "another trauma referral" I felt empowered to work with her. I felt connected, and I believed the connection was useful. However, after I read the letters Patricia's children had written to their deceased father, I could not bring myself to listen to the song again. When I did try, I couldn't. The emotion was too strong. The first playing of the song had unlocked my emotion and enabled connection, but the second playing started to flood me with emotion that I felt unable to manage. Thinking of Patricia's children, one of whom is not too dissimilar in age to my own and imagining myself in Patricia's shoes was difficult. Imagining this with the music added in was simply not bearable or something I was willing to allow myself to do. Realising just how unbearable it was to sit in Patricia's shoes was powerful. It made me realise just how distressed she must be feeling. If I cannot bear to be in her shoes for the duration of a short song, how does she cope day in, day out. I am lucky. I can turn off the music. I can shut the window into Patricia's world, which the music opened for me. However, Patricia is living with the overwhelming-ness of her situation every day.

The music enabled the transference of Patricia's emotion to me, without us even being physically present 
in the room. This has been a powerful realisation, which has inspired me to use music to enhance my emotional experience of clients.'

\subsection{Carly}

'I received a GP referral letter which described how Patricia was involved in a car accident where her husband Samuel died. I struggled to connect with the emotion in the referral. Instead I was fixated on the content, unanswered questions and how to help.

Whilst reading the psychologist's letter, I learned about Patricia's happy childhood, special time when she met Samuel, and the "idyllic" parenting of their children. However, this sense of happiness and security was shattered after the car accident. My mind went into the default drive of a clinical psychologist when I began to think about a formulation.

I sat in a meeting room in my lunch break ready to listen to the song sent to me. As soon as the music started I felt everything slow down as if all the unanswered questions, theoretical models and formulation left my overactive mind and faded behind the walls of the room. This was the first time I felt Patricia's heartbreak when the singer sang: 'I would walk all the way from Boulder to Birmingham If I thought I could see, I could see your face'.

The sense of guilt that Patricia felt for surviving and having fewer injuries than her children was captured by the singer: 'And the hardest part is knowing I'll survive'. I was moved to tears as I sat all on my own listening. I began to reflect on how alone I would feel without my partner in my life...It is interesting how a piece of music led me to connect with Patricia on a human level.

Patricia, as a music teacher, might benefit from using music to enable her to express herself and the psychologist noted that Patricia struggled to talk about the event. This led me to think about the use of music in therapy and how powerful it can be for both the people we work with to express their emotion in a medium that works for them as well as to help the professional to emotionally connect to the person in front of them, on a human level, from the heart.

I received Father's Day letters from the children and Patricia to the late Samuel alongside a KitKat chocolate bar. My heart went out to the children as I learned how alone they feel without their father and how much they miss him. After reading the Father's Day letters I learned the meaning behind the KitKat bar as the children referred to an invented place called 'KitKat Land' where the late Samuel would have all the things he liked. A sense of guilt swept over me; it started to hit me that I can eat the KitKat and Samuel will never experience one again. This led me to imagine the intensity of emotion Patricia might feel.

The use of letters, KitKat, and naming a special place of rest made me appreciate the power of using different mediums that engage the senses in my clinical practice. I am grateful that this exercise has strengthened the importance to stand back from labels and allow the space to work creatively with the people in front of me.'

\subsection{Understanding the Narratives}

Although it was respected that some description may be important, the focus of analysis was on the process of how people made sense of their experiences, and so thematic analysis was used to uncover primary themes across the narratives (Braun and Clarke, 2006). To ensure each voice remained independent, themes were elicited by the first author. An open-minded inductive data-driven approach was used. The analytic process involved a progression from description, where the data was organised to show patterns in semantic content and summarized, to interpretation, where an attempt was made to theorize the significance of the patterns and their broader meanings and implications (Patton, 1990). These themes were then individually shared with each author to ensure they resonated with their experience, which was confirmed before sharing the paper in its entirety with all authors. It should be noted the perspective of the first author may have influenced the elicitation and interpretation of themes; other themes and a differing focus could have been identified and elicited. The themes will be presented through the discussion, incorporating links to the literature.

\section{Discussion}

These reflective narrative accounts highlighted several recurrent and significant themes in explaining clinicians' experience of music to enhance the learning process and their clinical work. There were two parts to this process connection and understanding of a referral prior to, and following, hearing a song and receiving other creative mediums. Indeed, this vignette also benefited from the use of children's letters and KitKats to enhance the emotional meaning of 
loss for the family within the vignette. The themes elicited were: 'Empathy may not always be emotionally connected'; 'Becoming human: The connective power of music transporting to memories and emotion'; 'The need for protection: Shutting out the emotional world music opens up'; and 'Being an effective, congruent and humane practitioner'

Throughout we will consider how music and other mediums enhanced the learning process post qualification, exploring the scope for alternative methods of learning outside formal training contexts.

\subsection{Empathy May Not Always Be Emotionally Connected}

Every scenario within psychological referrals involves some type of struggle, often with associated distress. CPs are trained to formulate and derive hypotheses from the moment they read a referral letter - this is an important competency within the profession (BPS, 2016) so entrenched that as a qualified CP Carly stated, 'my mind went into the default drive of a Clinical Psychologist when I began to think about a formulation' (section 3.3). Professionally CPs work with distress day in and day out, entering into the profession with a desire to help. Indeed, on receiving the referral letter, similarly to Carly, Isabel stated: 'I thought I empathised for the person in the letter' (section 3.2). However, the immediacy of an empathic connection may not always occur; for example, on listening to the music Isabel realised that prior to this: 'the empathy was cold and lacking in emotion'. It seems crucial we acknowledge the propensity for this and compassionately understand why this occurs despite a desire not to. Was it due to an inability to be empathic, an unwillingness to cross personal and professional divides, or circumstances impacting on the ability to connect when clinicians were working in busy environments? Given CPs' selection and training process emphasises the ability to be empathic it may be the stresses CPs experienced in clinical practice (Nutt \& Keville, 2016) were having an impact on empathic connection. Music may be an accessible medium to counter this, even via long-distance learning methods, and this will now be explored.

\subsection{Becoming Human: The Connective Power of Music Transporting to Memories and Emotion}

Music can facilitate a re-connection with our emotions and values, and alongside this may simultaneously enable us to access empathy, otherwise the capacity to empathise may be 'lacking' (Isabel, section 3.2). Indeed, music can facilitate connection via the musical notes or through lyrics making it a musical and/or a language-based experience. This can enhance connections between our own and others' experiences. For example, only on hearing the music was Carly 'moved to tears' (section 3.3) and for Isabel 'the music enabled connection by enabling feeling' (section 3.2). Clearly music unlocks doors to personal and emotional connections highlighted by Katherine's memories of her grandparents (section 3.1) and Isabel's connection with her own children (section 3.2). Greater autonomic nervous system responses to short excerpts of music, evoking stimulating emotions, such as fear and happiness, has been demonstrated; this was lesser with sadness (Khalfa, Peretz, Blondin \& Manon, 2002). Yet, clearly these reflections highlighted intensity in the experience of 'sadness' evoked through a song (Isabel; section 3.2) to the extent that 'tears' were elicited (Carly; section 3.3). It could be that playing a whole song connected to a rich personal story of distress presented in the letters and already known to the listener evoked similar emotions within the listener/reader through enhancing meaning and, thus, empathy. This makes music a potentially useful learning tool when appropriately scaffolded for the learner.

Within sections 3.1 and 3.2 respectively, Katherine and Isabel highlighted the importance of the song to enable connection to the emotional experience of another person, yet, counter to this they also highlighted the professional necessity to switch off - when the thread between music, memories and emotion became too evocative. The link can be severed by 'turning' the music 'off', though may have been harder to avoid with the cumulative impact of the other mediums, such as the children's letters and KitKats. This leads us onto our next theme.

\subsection{The Need for Protection: Shutting out the Emotional World Music Opens up}

'If I cannot bear to be in her shoes for the duration of a short song, how does she cope day in, day out' (Isabel; section 3.2)

It appeared that similarly to CPs in training (Keville et al., 2018, p5 \& p8), qualified clinicians can still 'oscillat(e) between exposure' to distress 'and withdrawal' from it. In section 3.1 and 3.2 we can vividly experience this with Katherine and Isabel. Katherine explicitly highlighted this process in managing grief and loss. Here we see the tension between the empowerment the music brought to understanding the lived experience of another, to a sense of tipping into the 'overwhelming-ness' of the emotional experience Isabel highlighted. For example, 'the second playing started to flood me with emotion that I felt unable to manage' (Isabel). Both Katherine and Isabel needed to disconnect when the resonance or experience was too strong. Individuals naturally use music as a way of self-regulating emotions and distracting from difficult experiences (MacDonald et al., 2014). The way we used music to connect with distress meant avoidance was an unlikely option for some, and this was particularly important here with respect to the learning process when one must face the disconcerting boundary between knowing and not knowing to gain knowledge. Further, the ability to disconnect through music may be a fallacy; akin to our knowledge of the futility of experiential avoidance to 
manage emotions (Hayes et al., 2003). Even neurologically when connections are present, perhaps, we can never disconnect fully from the understanding or emotions music can evoke. For example, one study on those with focal brain lesions to areas of the brain normally associated with autonomic responses or areas required for subjective reports of emotional experience, showed those who do not have normal responses or arousal to music may still experience emotions from music; such that even when arousal or experience were compromised music could still be used for the social communication of mood and emotion (Johnsen, Tranel, Lutgendorf \& Adolph, 2009). Perhaps music may be a route to empathy for many of us.

CPs must develop the ability to connect and disconnect within their working routine to function in their busy working lives whilst simultaneously living their own lives carrying their own memories. Neither end of the extremes of connection or disconnection is necessarily helpful. Thus, it is crucial we enable those working clinically to connect enough to care about the people they see (empathy, compassion), and to care enough about their own well-being to disconnect at appropriate times (self-compassion, self-care); just as Isabel had to do following reading the letters (section 3.2). This is akin to the process of connecting and letting go in mindfulness practice (Kabat-Zinn, 2006). Within clinical contexts, music can modify perceptions of pain increasing the ability to cope (Brown, Chen \& Dworkin, 1989). Thus, there is utility for the use of music to facilitate disconnection, alongside the use of music to connect with, and process, experiences. Indeed, it is believed there is an emotion processing network in response to music that may facilitate this, integrating areas of the brain involved in reward experience, movement, attention, and in appraising and processing emotions (Mitterschiffthaler, Fu, Dalton, Andrew \& Williams, 2007).

The narratives in section 3 highlighted the controllability that music enabled in the processes underpinning empathy, notably the ability to connect with the emotional world of people in distress whilst protecting oneself from being consumed by it. Knowing the subtleties of the process of connection and avoidance also enhances awareness enabling the capacity for informed choices; that is, knowing when to disconnect, and when to connect, and responding flexibly within a dimension of avoidance and connection (Keville, Byrne, Tatham \& McCarron, 2008). This is particularly important in a learning process, and within clinical work, as all these accounts highlighted. Professionally, there was still space for compassion which came from the knowledge that the person living the experience cannot switch off and here, as Katherine stated in section 3.1, the professional may 'model' the ability to 'connect to an emotional experience without becoming overwhelmed by it'.

\subsection{Being an Effective, Congruent and Humane Practitioner}

This leads us to our final theme based on the fundamental value base of professionals particularly demonstrated in these accounts. The desire to be effective, congruent and humane practitioners was striking, in sections 3.3 and 3.1 respectively, when Carly stated the value of connecting at 'a human level, from the heart' and Katherine stated the value of connecting 'with both our client's and our own humanity'. Indeed, there was a personal honesty within the accounts derived via a reflective training process and working in clinical practice; this openness maintains and enhances reflective practice skills. Life-long learning has been cited as a human right (Schuller \& Watson, 2009). These materials were shared remotely - the value of lifelong and distant learning is we can undertake this anywhere through any medium, and this indirect means of learning is, therefore, highly accessible enabling reconnection with one's core values post-qualification. Indeed, it is crucial we facilitate and support this learning, to enable clinicians to retain compassion towards those they see and self-compassion towards themselves to facilitate self-care. Compassion focused therapy can be effective with complex experiences (P. Gilbert, 2005) and understanding and empathy can also be achieved through the learning process itself via compassion focused pedagogies (T. Gilbert, 2018), and the use of personal experiences to construct learning materials (Keville, submitted).

\section{Concluding Comments}

\subsection{Scaffolding Lifelong Learning by Compassionately Embracing Our Own and Others' Emotions via Music}

The intensity of music and emotion can enable almost any person to use music therapeutically, particularly for processing emotions. Yet, alongside this we must be mindful that high work-loads (Nutt and Keville, 2016) with increasingly complex trauma-based work may result in compassion burnout and vicarious traumatisation for those working in and/or managing clinical practice. Pertinent to any learning method is the concept of scaffolding (Wood, Bruner \& Ross, 1976). Enabling the ability to connect and disconnect with distress is a lifelong learning process crossing personal and professional boundaries; compassion is essential within this process, as is appropriate scaffolding of learning materials. Further, facilitating this ability through compassionate pedagogies might serve two purposes; firstly, acknowledging and processing past personal experiences may enable clinicians to become more resilient and effective practitioners; and, secondly, truly enhancing one's connection and understanding with the distress of others may enhance efficacy. It is crucial that CPs have opportunities to do this as experience may be a factor in the confidence level of CPs to fully and compassionately embrace connecting with distress in the way we are suggesting here. 
Alongside distance learning methods, supervision is another way of achieving this post-qualification, where it can serve a learning function and a space to enable reflective practice (BPS, 2016). CP intertwines supervision in its professional training pre and post-qualification (BPS, 2016); this is vital in maintaining and developing lifelong learning in reflective practitioner skills. It is crucial to acknowledge this alongside the value of compassionate spaces as the focus on face-to-face contact with people can mean supervision becomes a secondary requirement, minimising the value of this important process in our quality control and CPD. CPs value supervision, yet current service demands make this difficult to argue for in the climate of austerity (Nutt and Keville, 2016). It is essential we maintain these aspects of working practice for CPs and other front-line professionals.

\section{Acknowledgements}

Special thanks go to 'Mum' for allowing us to use your experiences and children's letters to form the heart and soul of this vignette. Just as songwriters bring emotional honesty to their music and lyrics, you have gifted learning for clinicians through your own experiences - those they might not otherwise have connected with. We cannot take away your sorrow, but we can learn from it.

\section{References}

British Psychological Society (2016). Standards for the accreditation of Doctoral programmes in Clinical Psychology. Leicester: British Psychological Society.

Brown, C. J., Chen, A. C. N., \& Dworkin, S. F. (1989). Music in the control of human pain. Music Therapy, 8, 47-60. https://doi.org/10.1093/mt/8.1.47

Clark, D. M., Layard, R., Smithies, R., Richards, D. A., Suckling, R., \& Wright, B. (2009). Improving Access to Psychological Therapy: Initial Evaluation of Two UK Demonstration Sites. Behaviour Research and Therapy, 47, 910-920. https://doi.org/10.1016/j.brat.2009.07.010

Flores-Gutiérrez, E. O., Díaz, J. L., Barrios, F. A., Favila-Humara, R., Guevara, M. A., del Río-Portilla, Y., \& Corsi-Cabrera, M. (2007). Metabolic and electric brain patterns during pleasant and unpleasant emotions induced by music masterpieces. International Journal of Psychophysiology, 65, 69-84. https://doi.org/10.1016/j.ijpsycho.2007.03.004

Gilbert, P. (2005). Compassion: Conceptualisations, research and use in psychotherapy. East Sussex: Routledge.

Gilbert, T., Doolan, M, Beka, S., Spencer, N., Crotta, M., \& Davari, S. (2018). Compassion on university degree programmes at a UK university: The neuroscience of effective group work, Journal of Research in Innovative Teaching \& Learning, https://doi.org/10.1108/ JRIT-09-2017-0020

Hayes, S. C., Strosahl, K. D., \& Wilson, K. G. (2003). Acceptance and Commitment Therapy. An Experiential Approach to Behaviour Change. New York: Guilford Press.

Johnsen, E. L., Tranel, D., Lutgendorf, S., \& Adolph, A. (2009). Neuroanatomical Dissociation for Emotion Induced by Music. International Journal of Psychophysiology, 72(1), 24-33. https://doi.org/10.1016/j.ijpsycho.2008.03.011

Kabat-Zinn, J. (2006). Mindfulness-Based Interventions in Context: Past, Present, and Future. Clinical Psychology-science and Practice, 10(2), 144-156. https://doi.org/10.1093/clipsy.bpg016

Keville, S. (submitted). You have come by way of sorrow: enhancing empathy in clinicians by using personal experiences to construct professional learning materials, Journal of Patient Experience,

Keville, S., Byrne, V., Tatham, M., \& McCarron, G. (2008). Cognitive Behaviour Group Therapy for Obesity and Binge Eating Disorder. In Buckroyd, J. and Rother, S (Eds). Psychological Responses to Eating Disorders and Obesity. Chichester: Wiley \& Sons Ltd.

Keville, S., Nutt, K., Brunton, I., Keyes, C., \& Tacconelli, E. (2018). So many lifetimes locked inside: reflecting on the use of music and songs to enhance learning through emotional and social connection in Trainee Clinical Psychologists. Reflective Practice, 19(3), 1-13. https://doi.org/10.1080/14623943.2018.1479687

Khalfa, S., Peretz, I., Blondin, J. P., \& Manon, R. (2002). Event-related skin conductance responses to musical emotions in humans. Neuroscience Letters, 328, 145-149. https://doi.org/10.1016/S0304-3940(02)00462-7

MacDonald, R. A. R., Kreutz, G., \& Mitchell, L. (Eds) (2014). Music, Health and Wellbeing. Oxford: Oxford University Press.

Miranda, D., Gaudreau, P., Debrosse, R., Morizot, J., \& Kirmayer, L. J. (2015). Music Listening and Mental Health: Variations on Internalizing Psychopathology.

Mitterschiffthaler, M. T., Fu, C. H. Y., Dalton, J. A., Andrew, C. M., \& Williams, S. C. R. (2007). A Functional MRI 
Study of Happy and Sad Affective States Induced by Classical Music. Human Brain Mapping, 28, 1150-1162. https://doi.org/10.1002/hbm.20337

Nutt, K., \& Keville, S. (2016). '.. you kind of frantically go from one thing to the next and there isn't any time for thinking any more': A reflection on the impact of organisational change on relatedness in multidisciplinary teams. Reflective Practice, 17(2), 221-232. https://doi.org/10.1080/14623943.2016.1159552

Patton, M. (1990). Qualitative evaluation and research methods ( $2^{\text {nd }}$ Ed.). Beverly Hills, CA: Sage.

Purdon, C. (2004). Empirical investigations of thought suppression in OCD. Journal of Behavior Therapy and Experimental Psychiatry, 35, 121-136. https://doi.org/10.1016/j.jbtep.2004.04.004

Schuller, T., \& Watson, D. (2009). Learning through life: Inquiry into the future for lifelong learning: summary. National Institute of Adult Continuing Education (England and Wales), Leicester.

Shankar, S., Nolte, L., \& Trickey, D. (2017). Continuing bonds with the living: bereaved parents' narratives of their emotional relationship with their children. Bereavement Care. https://doi.org/10.1080/02682621.2017.1386400

Wells, A. (2000). Emotional Disorders and Metacognition. Chichester: John Wiley \& Sons Ltd.

Winter, D. (2017). Resilience has become a way of life in Sierra Leone, now mourning hundreds lost in mudslide. The Conversation. Retrieved from:

http://theconversation.com/resilience-has-become-a-way-of-life-in-sierra-leone-now-mourning-hundreds-lost-in-m udslide-82594

Wood, D., Bruner, J. S., \& Ross, G. (1976). The role of tutoring in problem solving. Journal of Child Psychology and Psychiatry, 17(2), 89-100. https://doi.org/10.1111/j.1469-7610.1976.tb00381.x

\section{Copyrights}

Copyright for this article is retained by the author(s), with first publication rights granted to the journal.

This is an open-access article distributed under the terms and conditions of the Creative Commons Attribution license which permits unrestricted use, distribution, and reproduction in any medium, provided the original work is properly cited. 